\title{
Hip Fracture, CTCAE
}

National Cancer Institute

\section{Source}

National Cancer Institute. Hip Fracture, CT CAE. NCI Thesaurus. Code C143546.

A finding of traumatic injury to the hip in which the continuity of either the femoral head, femoral neck, intertrochanteric or subtrochanteric regions is broken. 